\title{
Integrating Ethics in AEC Education
}

\author{
Gouranga C. Banik, Ph.D., P.E. \\ School of Architecture, Civil Engineering Technology and Construction \\ Southern Polytechnic State University \\ Marietta, GA 30060
}

\begin{abstract}
The construction industry needs to create a more professional work environment in order to attract the best and brightest people that the industry will need in the future. This type of professional work environment can only be created by strict adherence to a strong code of ethics. A trend toward a more ethical and professional work environment will allow the construction industry to better compete for the talented and experienced people that will be needed in the future. The industry has growing concern about ethical behavior of new employees and prospective employees. The industry typically states that one of their most valuable assets is their reputation and that their reputation is directly related to their ethical behavior. The construction industry as a whole will be better off when the majority of the employees will become aware of their ethical responsibilities to the people, the workers and the industry. This article describes the importance of ethics in the AEC profession; how it can be integrated into the undergraduate curriculum; and how it can be taught.
\end{abstract}

Key Words: Ethics, AEC Education, Construction, Curriculum

\section{Introduction}

Most Architecture-Engineering-Construction (AEC) students find themselves ill-equipped and unprepared to handle difficult ethical problems in the workplace due to a lack of adequate exposure in their education. Proper ethical training and education helps the students to recognize dilemmas, to employ moral imagination and obligation, and to recognize compartmentalization when addressing these dilemmas. It also enables professionals to differentiate between common morality and professional ethics (Harris, Davis, Pritchard, \& Rabins, 1996).

The major approach to teach engineering-technical ethics follows pedagogical practices of law, medicine and business (Self \& Ellison, 1998) case-studies, which are now being used increasingly to teach design and construction as well as ethics (Harris, Davis, Pritchard, \& Rabins, 1995). Case studies provide an opportunity for a kind of vicarious mentoring, in which the student is taken through a compressed version of a real dilemma, debates alternatives, makes a choice, and is shown expert solutions. It is often productive to use codes with these cases to serve as a starting point for developing a deeper understanding of ethical dilemmas. 
Unfortunately, hypothetical cases sometimes lack credibility with students--they merely mentally concede to engage the case because they are required to, but then tell themselves that practitioners never actually encounter real ethical dilemmas, a case in point of compartmentalization. Hence, in order to further the roster of excellent case materials already in existence, a venture in more real-world, in-depth cases also give students undeniable evidence that practicing AECs do find themselves struggling with ethics (Dorsey, 1999). These cases also enable students to labor with difficult and multiple dilemmas, which they themselves might encounter. The conflicts, intricacies and complexities of situations, not uncommon in the real construction world, offer an effective exacting exercise in creativity, management and moral imagination.

It is sometimes more useful to create real-hypothetical hybrid cases, by changing names or altering circumstances. This is necessary when the outcome of the real case is known. Consider the recent Columbia disaster case. Very few students, even when given all the information possessed at the time, will argue in favor of launching the Shuttle again and again even with the inherited risk. They know what happens if the shuttle fails. If we want to give options to launch the shuttle vs. drive race cars, they are more likely to opt to race the car considering safety, and this will lead to a deeper discussion of the ethical and organizational issues (Vaughn, D, 1996).

In addition to crisis cases, where the AEC student is backed into a dilemma late in the design process that involves whistle-blowing and resignation as possible options, there is a need for cases involving preventive measures early in the design and construction process. The advanced technology has created enormous environmental, social, and cultural stresses, and enormous opportunities for improving the quality of projects. Often AECs fail to see their part in this big picture. But then who designs energy systems that can be efficient and environmentally sensitive, manage the project with safety and quality or use up valuable natural resources and produce pollution? Ethical choices in construction are typically made at the beginning of the design process; therefore, we need case studies that pose ethical, managerial and technical dilemmas that require students to exercise moral imagination from the beginning of the design process towards the end of project completion.

Additionally, encountering a carefully crafted story and playing out a role in that story gives students an experience they may remember well after graduation (Banik, 2002). If instructors manage to engage the students to this level, much will have been done to enhance their moral reasoning and moral imagination when addressing ethical dilemmas as AECs in the future.

As a receiver of a grant, the author proposes to develop a research and educational experience that will focus on producing construction graduate students who will be able to understand complex technological and managerial systems, and develop case studies from which students can learn real world construction-related ethical problems. The study is focused to transform students into ethical practitioners who will reflect on the consequences of their designs and constructions.

Recent innovations of information technology and managerial dilemma are exerting enormous social, cultural and environmental pressures to both students and practitioners to make it right at the first time. But then who designs the building that can not complete in time or within costs? Who manages the projects that lead to accidents? Who provides technologies ignorant of cultural and political context? AECs make these choices. These choices are typically made at the design and project implementation stages; therefore, we need case studies that pose ethical, managerial and technical dilemmas that require students to exercise moral imagination from the beginning of 
the design process forward. These types of preventive case studies, in contrast with crisis ethics commonly found in most cases, where the AEC finds himself already backed into a corner with no other recourse including whistle-blowing and resignation.

\section{Examples of Case Studies}

With the support of the University, the author is trying to develop case studies which cover ethical dilemmas in construction courses. Some of the examples listed below:

\section{Case: Construction Manager's (CM) Recommendation for Full-Time, On-Site Project Representatives}

Facts: The client plans a project and hires CM X to furnish complete construction management (CM) services for the project. Because of the potentially dangerous nature of implementing the design during the construction phase, $\mathrm{CM} \mathrm{X}$ recommends to the client that two full-time, on-site project representatives be hired for the project to complete the project in time, within costs, with safety and quality. After reviewing the completed project plans and costs, the client indicates to $\mathrm{CM} \mathrm{X}$ that the project would be too costly if CMs need to be hired. CM X proceeds with his work on the project without hiring site representatives and keep quiet.

Was it ethical for CM X to keep quiet knowing that the client would not agree to hire a full-time project representative although there is a danger of hazardous works?

According to Construction Management Association of America (CMAA)- Construction Manager (CM) will serve their clients with honesty, integrity, competence, and objectivity, establishing a relationship of trust and confidence and furnishing his best skills and judgment consistent with the interests of his client."

NSPE references state: Code of Ethics-Section II.1.a.:"Engineers shall at all times recognize that their primary obligation is to protect the safety, health, property, and welfare of the public. If their professional judgment is overruled under circumstances where the safety, health, property, or welfare of the public are endangered, they shall notify their employer or client and such other authority as may be appropriate."

Section III.1.b.:"Engineers shall advise their clients or employers when they believe a project will not be successful."

Discussion: The issue presented in this case goes to the heart of the Code of Ethics. A code of ethics is of course a statement of commitment from a particular profession to assist its members in the protection of the public health and safety. There is probably no better or more valuable purpose for a code of ethics. AECs, recognize that the reason for regulation and licensure is the protection of the public health and safety. However, AECs have the desire and commitment to "go the extra mile," and voluntarily commit themselves to a higher standard of conduct.

This point is quite relevant to the discussion of this case. Under the facts, CM X made a professional judgment based upon education, expertise, and experience that two full-time, on-site project representatives would be necessary during the construction phase of the project because of the dangerous nature of the project. This was presumably a determination which was made after a careful and thorough weighing of the costs of the full-time, on-site project representatives 
versus the benefits of having such representatives. It may very well be that the state registration board's rules of professional conduct may not specifically require CM X to make the determination that was made; however, it appears that the NSPE/AIA/CMAA/AIC Code of Ethics does contain provisions which address this point. The code requires the CM to inform a client when the CM believes that a project will not be successful. The term "successful" includes not merely the structural and economic success of a project but also the success of the project from a safety standpoint. It is clear from the facts that CM X did notify the client of the need to hire full-time, on-site project representatives for the construction phase of the project. Therefore, CM X did act in accordance with code.

NSPE/CMAA admonishes engineers/CMs to recognize that their primary obligation is to protect the public safety, health, property, and welfare. Under the facts of this case, it appears that CM X did not recognize this primary obligation. CM X's use of best professional judgment, made a recommendation based upon what was believed to be consistent with that obligation. However, when cost concerns were raised by the client, CM X abandoned the ethical duty and proceeded with work on the project. It appears that CM X acted in a manner that suggests that the primary obligation was not the public but the client's economic concerns. For that reason, Engineer X was in violation of the particular Section.

When the client indicated that the project would be too costly if a full-time, on-site project representative were hired, CM X acceded to the client's wishes and proceeded with the work despite the fact that $\mathrm{CM} \mathrm{X}$ believed that to proceed, without an on-site project representative, would be potentially dangerous. CM X did not force the issue or insist that project representatives be hired. Instead, CM X "went along" without dissent or comment. If CM X's ethical concerns were real, which we presume they were, CM X should have insisted that the client hire the on-site project representatives or refuse to continue to work on the project. While this might appear to be a harsh result, we think that such an approach is the only one that would be consistent with the Code of Ethics.

Learning: It was unethical for CM X to proceed with work on the project knowing that the client would not agree to hire full-time, on-site project representatives.

\section{Project Management: Scenario}

A general contracting firm has been offering services for thirty years, always completing project on time and within budgets. This firm often turns down work, since it is in such a great demand in the marketplace, and had never been involved in an accident and/or in a lawsuit.

The owner suddenly died, and the business was turned over to his son. The son had a good construction education and 10 years of experience working with his father. Within two years after the death of his father, the firm had 2 major and 7 minor accidents and was engaged in three lawsuits, resulting in substantial financial losses.

Identify the probable causes that led to his failure.

1. Is the new owner ethically responsible for the worker accident on his sites according to CMAA/AIC/AIA/NSPE?

2. If so why and why not?

3. As a new owner, will you try to take care of safety of your employees even though you

Proceedings of the 2003 American Society for Engineering Education Annual Conference \& Exposition Copyright $(\mathrm{C}$ 2003, American Society for Engineering Education 
are losing money in your projects?

4. Do you feel that you are socially responsible to the victim's family for any accidents in your construction sites?

Some other examples of these ethical judgments might include the followings:

Is it appropriate for a contractor to front-load the schedule of values, or the unit price line items in a contract in order to maintain a positive cash flow?

Is it appropriate for a general contractor to solicit a lower bid from a subcontractor by revealing the bid amount from the subcontractor's competitor?

Is it appropriate for an owner, contractor, or subcontractor to delay payment to their contracting partners and suppliers in order to gain interest on the delayed payment amount?

These cases encourage students to see the ethical and social issues embedded in the design of and construction of complex projects. The goal is to produce AEC professionals, who understand that invention, design and discovery involve linking the technical, the social, the managerial and the ethical aspects. Such a designer/contractor will need to be a reflective practitioner, capable of engaging in moral imagination.

These cases have been tailored in several construction classes, including a construction seminar class and construction safety class that require discussion of ethical issues. The author generally describes the cases in interesting and relevant way so that interaction takes place in the classes. Each case comes with a teaching note that includes the best practices that emerge from classroom piloting.

Ethical judgments are the basis by which many of the decisions in the construction industry are made. In Construction Risk Analysis class, students begin by identifying a real-world example in which practitioners are struggling to solve problems involving closely intertwined technical, managerial, social and ethical issues. Examples already mentioned include construction without proper supervision, implementing safety without giving proper training and supplying safety equipments or bidding as misrepresented minority enterprise to get the work and so on.

Concurrent with this problem identification phase, students enroll in core construction courses, such as estimating, building codes, project management and construction law which address problem outscoping, management, social issues, goal setting, and quantitative and qualitative modeling. The core courses provide a framework and basic tools for analyzing the ethical problems.

\section{Conclusions}

Every professional discipline has its ethical issues and responsibilities. The ideal system to teach ethics would be one in which students from any department could sign-up for an ethics class that should be taught by experienced senior multi-disciplinary faculty, ready to assist faculty in the department with special seminars, student supervision, places to publish and potential sources of funding. The classes should be multidisciplinary because ethics does not depend on a particular concentration. Also, it should always depend on students who want to learn and apply it to the real world. Faculty must teach them by example as well as by lectures. 
Every student is going to face ethical issues throughout his/her career. It is critical that they be prepared for these decisions. They must understand the impact their decisions have on the products or projects they are working on, the customer who buys the product, the owner who finances the project and their reputation as a designer/builder and as a person. AECs through their important work have vast impact on the lives of many people through health and safety issues as well as financial issues.

\section{Bibliography}

- American Association of Architects (AIA). www.aia.org.

- Banik, G.C. (2003) "Writing an Effective Case Study". Proceedings: $39^{\text {th }}$ Associated School of Construction (ASC) Annual Conference, Pp. 1-7, Clemson University, Clemson.

- Construction Management Association of America (CMAA). www.cmaa.org.

- Dorsey, Robert (1999) “Case Studies in Building Design \& Construction”. Prentice Hall, NJ.

- Frickleton, J. E. (1999). "Case Studies in Engineering Ethics”. American Society for Engineering Education, Milwaukee, NM, ASEE.

- Gorman, M. E., J. Stocker, et al. (1997)."Using detailed, multimedia cases to teach engineering ethics". American Society for Engineering Education, Milwaukee, WI, ASEE.

- Harris, C. E., Jr., M. Davis, et al. (1996). "Engineering ethics: What? Why? How? and When?" Journal of Engineering Education 85(2): 93-6.

- Harris, C. E., M. S. Pritchard, et al. (1995). "Engineering ethics: Concepts and cases". Belmont, CA, Wadsworth.

- Lynch, W. T. (1997). "Teaching engineering ethics in the United States." IEEE Technology \& Society Magazine(Winter): 27-36.

- Martin, M. W. and R. Schinzinger (1989). Ethics in Engineering. New York, McGraw Hill.

- National Society of Professional Engineering (NSPE). www.nspe.org.

- Self, D. J. and E. M. Ellison (1998). "Teaching engineering ethics: Assessment of its influence on moral reasoning skills." Journal of Engineering Education 87(1): 29-34.

- $\quad$ Taft H. Broome, J. and J. Pierce (1997). "The Heroic Engineer." Journal of Engineering Education 86(1): 51-55.

- Vaughan, D. (1996). The Challenger Launch Decision. Chicago, The University of Chicago Press. 


\section{Gouranga C. Banik, Ph.D., P.E.}

Gouranga C. Banik is an Associate Professor of Construction Program at Southern Polytechnic State University in Marietta, Georgia. Dr. Banik completed his Ph.D. in Civil and Construction En gineering from Iowa State University. He has eleven years working experience in both private and public sector as an engineer and/or construction manager. He is a registered professional engineer. Dr. Banik has twelve refereed publications in the journals of civil engineering and construction management. He presented some of his research in several wellknown and peer reviewed conferences like ASEE, ASCE, ASC, WEFTEC and CIB, and published articles in those conference proceedings. He presented his research all over the world including the United States, Canada, Greece, and Philippines. 